\title{
Design considerations and solutions in rapid-prototyping an ultraviolet reactor for ice borehole disinfection
}

\author{
Peter W. KEEN, ${ }^{1}$ Mario P. BRITO ${ }^{2}$ \\ ${ }^{1}$ Keen Marine Ltd, East Cowes, Isle of Wight, UK \\ E-mail: pwk@keen-marine.com \\ ${ }^{2}$ Natural Environment Research Council, Cambridge, UK
}

\begin{abstract}
Antarctic subglacial lakes are of great interest to the science community. These systems are considered to be in pristine condition, potentially harbouring an environment containing undisturbed sedimentary sequences and ecosystems adapted to cold oligotrophic environments in the absence of sunlight. Gaining access to subglacial lakes presents major technological challenges. To comply with conventions covering the exploration of pristine Antarctic environments, access should be conducted so the lake is not contaminated in any way. Consequently, all equipment to enter the lake must be sterile and the entrance should isolate the lake from the external environment. Currently, clean access to these environments is achieved using a hot-water drilling system. Differences between the hydraulic pressure head of the lake and the glacial surface result in a section of the borehole being air-filled. It is imperative that this section is disinfected prior to introducing any sampling equipment. This paper describes the design process involved in rapid-prototyping an ultraviolet (UV) disinfection reactor for achieving this goal. Considerations such as UV output, physical constraints, temperature management, and deployment procedures are assessed. We present a design that addresses these considerations.
\end{abstract}

KEYWORDS: Antarctic glaciology, glaciological instruments and methods, ice biology, subglacial lakes

\section{INTRODUCTION}

Antarctic subglacial lakes were discovered rather by accident during a flight to determine landmarks to aid flight navigation in Antarctica (Robinson, 1960). Several airborne surveys followed and, to date, 379 subglacial lakes have been catalogued (Wright and Siegert, 2012). Many of these lakes were formed millions of years ago at the same time as the Antarctic ice sheet. They are sustained predominantly by basal ice melt due to pressure effects from compression by overlying ice and have, in many cases, been sealed from free exchange with the atmosphere for millions of years (Dowdeswell and Siegert, 2003; NRC, 2007). Since their discovery there has been interest in accessing these lakes and exploring them with two primary goals: to find and understand the life that may inhabit these pristine environments and to recover stratigraphic records that may be contained in the sediments.

Lake Ellsworth is a subglacial lake in West Antarctica located at $78^{\circ} 58^{\prime} 34^{\prime \prime} \mathrm{S}, 090^{\circ} 31^{\prime} 04^{\prime \prime} \mathrm{W}$ within the uppermost catchment of Pine Island Glacier. It is formed at the bottom of a deep trough approximately $3000-3250 \mathrm{~m}$ below the ice surface (Siegert and others, 2004; Vaughan and others, 2007). The Lake Ellsworth Project is a consortium of mainly British researchers and is an initiative undertaken by the UK Natural Environment Research Council (NERC) to sample water and sediment in Lake Ellsworth (Siegert and others, 2012).

There is still some uncertainty whether subglacial lakes exist in an open or closed system (Brito and others, 2013). Given the pristine state of these lakes, both the Scientific Committee on Antarctic Research (SCAR; Alekhina and others, 2011) and the US National Research Council (NRC) Committee on Principles of Environmental Stewardship for the Exploration and Study of Subglacial Environments (CPESESSE) (NRC, 2007) recommend that gaining access to subglacial lakes should not contaminate the existing ecosystem and, in particular, that equipment entering the lake should not contain in excess of the minimum concentration of microbes in the basal ice being passed through (Recommendation 7), suggesting, based on evidence available at the time, that this was in the order of $10^{2}$ cells $\mathrm{mL}^{-1}$ (see also Siegert and others, 2012).

At present, an attempt at clean access to Subglacial Lake Ellsworth has been made using a hot-water drilling system (Makinson, 1994). This drilling technique uses recirculated meltwater to form a borehole by pumping it through a nozzle as this is progressively lowered through the ice. The technique involves the formation of a reservoir chamber close to the glacier surface but below the predicted hydrostatic pressure head of the lake. Two shafts connect with the chamber from the surface, one extending to the lake for sampling, the other terminating in the chamber through which meltwater is drawn up to supply the drilling nozzle. The hydrological water level of subglacial lakes can vary, but it is expected that the upper section of the lake access shaft will be air-filled, and in the case of Lake Ellsworth this is estimated to be $\sim 300 \mathrm{~m}$ (Vaughan, and others, 2007; Siegert and others, 2012). This shaft is susceptible to contamination from airborne bacteria that can drop in from machinery, personnel and the environment during the drilling process before the shaft is sealed off from the environment with an airlock. Between installing the airlock and introducing presterilized equipment it is imperative to take measures to decontaminate this space.

This paper presents work undertaken to design an ultraviolet (UV) reactor that can be lowered down the shaft to decontaminate the air-filled section once it has been isolated from the external environment by an airlock and prior to the introduction of any sampling equipment. 


\section{GENERAL CONCEPT}

The design of the reactor was based around cylindrical UV reactors used to disinfect wastewater (Qualls and Johnson, 1983; Bekdash and others, 1996; Gardner and Shama, 1999; Bolton, 2000) since the constraining aperture for introducing equipment into the borehole was a circular hole in the base of a sterile airlock and because the borehole shaft would be roughly circular. This aperture was $20.0 \mathrm{~cm}$ in diameter. All sampling equipment entering the borehole had to pass this restriction. The reactor unit was to be lowered down the borehole on a conducting tether terminating in a connector common to all powered equipment deployed down the shaft.

The design paradigm was to create a high-output UV source using a quartz glass cylinder that had been reserved for the consortium, being of an appropriate length and diameter to comply with the constraints of the airlock (personal communication from N. Rundle, 2012). The output needs to be high enough to deliver a sufficient UV dose efficiently within time allocated to it out of the time available to achieve all the sampling objectives. Calculations are presented further below that help quantify expected doses in terms of lamp output and target exposure times. The apparatus also required a way of detecting when the unit contacted the water surface at the end of the air-fill section of the shaft and needed protection from water ingress should it be immersed at this point.

\section{DESIGN CONSIDERATIONS}

\subsection{Quartz glass supply}

The quartz glass cylinder, the sleeve, was an 'end of line' offthe-shelf product $95.3 \mathrm{~cm}$ long and of varying outer diameter between 16.82 and $16.88 \mathrm{~cm}$. It had a nominal $5 \mathrm{~mm}$ wall thickness along the majority of its length. Dimensions can vary considerably with this product.

Because drawing quartz glass of this size is a less than precise art, and the entire apparatus was to be designed around a nominally standard piece of quartz, fitting tolerances between the flanges and glass, to accommodate 0 -ring seals, were kept relaxed so that if at some point in the future a replacement was required there was a good chance it would fit.

The time frame set by the consortium made this a high risk to the project since no spare was available within the deadlines for shipping to the Antarctic. Consequently the quartz sleeve was treated with extraordinary care to protect it from physical damage.

Fortunately, quartz is more robust from a thermal perspective and has an extremely low thermal coefficient of expansion, $5.5 \times 10^{-7}{ }^{\circ} \mathrm{C}^{-1}\left(20-320^{\circ} \mathrm{C}\right)$, with an ability to undergo large, rapid temperature changes without cracking (De Jong and others, 2000). This gave us assurance that, while it may be relatively hot through absorption of heat produced by the UV lamps, the quartz would not shatter and should remain intact even if entering near-freezing water at the hydrostatic pressure head.

\subsection{Power}

Based on high UV output, price, physical dimensions and immediate availability, 12 low-pressure mercury (LPM) tubes could be accommodated within the quartz sleeve, controlled by electronic dual lamp ballasts housed in another section of the lamp assembly. This determined the power requirement for the reactor. Power was supplied to the unit by a Glassman LP6000 power supply through $4000 \mathrm{~m}$ of multicore tooling cable (Cortland Fibron BX) in the form of a d.c. voltage at a nominal 8.0 A. Because of the voltage line loss over that distance, d.c. power was fed at $240 \mathrm{~V}$ to achieve a starting voltage of $180 \mathrm{~V}$ d.c. at the reactor to power the ballasts and the lamps. The advantage of using electronic ballasts is that they can operate on a d.c. voltage, obviating the need to convert the supply to a.c. This simplified the circuit design considerably.

When a fluorescent lamp 'strikes', the ionizing mercury vapour forms a low-impedance pathway to the high voltages supplied from the ballasts (Gluskin, 1999). This effect momentarily draws high current that settles to a lower usage, regulated by the ballast, once the lamp has struck. If all six ballasts struck their lamps simultaneously, the current required would exceed what the power supply was capable of supplying. However, the simple power distribution system was, in a sense, self-regulating because the time constants for components within the starting circuits of individual ballasts will be slightly different as a result of resistance and other manufacturing differences. Consequently, the ballasts do not draw the available current evenly at start-up. Those not receiving sufficient current will be unable to strike until other ballasts regulate their lamp current to a lower demand once struck, and free resources. This produces, de facto, a sequential start-up.

\subsection{Temperature management}

UV output from the lamps is temperature-dependent, and peak output of the lamps occurs at a working temperature corresponding to the lamp wall temperature, $\sim 35^{\circ} \mathrm{C}$. Lamp output efficiency drops at temperatures over $48-50^{\circ} \mathrm{C}$, and operating lamps outside the designed temperature range can reduce their lifespan as well as their output. This drop in efficiency also causes the ballasts to run hot (Clancy, 1993; Graovac and others, 1998).

Under normal operating conditions, fluorescent lamps rely on airflow over the surface to prevent heat building up. Additionally the ballasts have a thermal cut-out at $70^{\circ} \mathrm{C}$ and require protection from temperatures in excess of this. Consequently, because the lamps were in a sealed enclosure, one factor driving the design was to provide a means of losing waste heat to the environment. A large temperature gradient between the operating environment $\left(\sim-18^{\circ} \mathrm{C}\right)$ and the reactor should work in the design's favour.

To aid the dissipation of heat, ducts and a set of internal concentric tubes allow cooling air to flow through the inside of the reactor (see Fig. 1). The inlet ducts on the lower flange were angled so there would be forcing of influent air as the reactor descended the shaft. The centremost tube conducted cables for power and signal while the surrounding tube provided the space through which cooling air could flow. The ballasts were positioned in the lower, coolest, part of the assembly. The central (cable) duct was sealed at either end by a gland (IP68) to prevent water ingress to the electrical spaces should the lamp be immersed in water at the bottom of the air-filled section of the borehole.

\subsection{Water contact switch}

Since the reactor was required to transit the entire airspace to the air/water interface it was anticipated it would come into contact with water. This defined a requirement to make provision for this eventuality. A common method for doing 


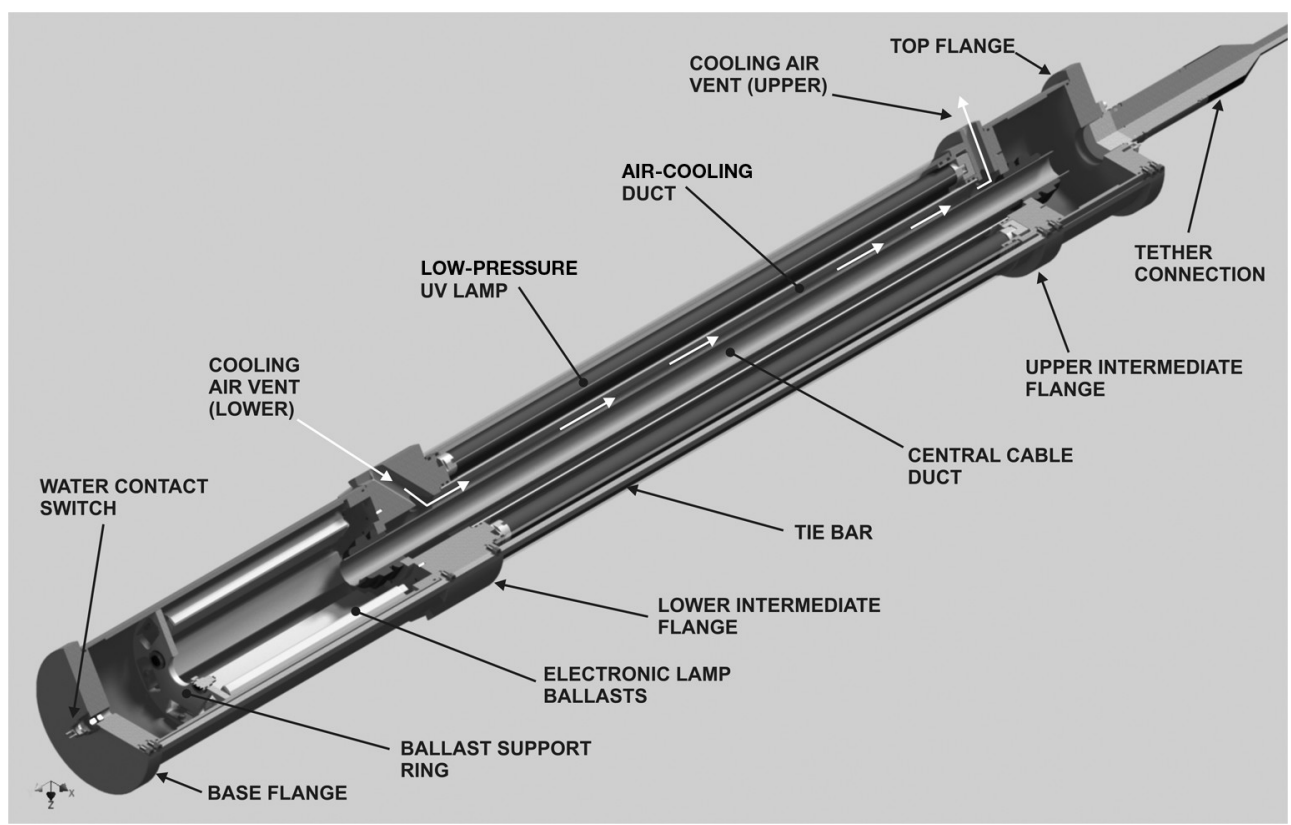

Fig. 1. Three-dimensional CAD cut-away drawing showing major structural and electrical elements of the reactor assembly, as well as indicating the cooling airflow through the unit during operation.

this is to use a simple conductivity sensor, formed of two exposed electrodes energized with a voltage between them as a water contact switch connected to a meter or alarm of some sort in the operator area.

It was anticipated that the conductivity of the borehole water would be low. Previous studies indicate that the glacial meltwater is likely to be between the conductivity of distilled water $\left(10 \mu \mathrm{S} \mathrm{cm}^{-2}\right)$ and tap water $\left(100 \mu \mathrm{S} \mathrm{cm}^{-2}\right)$, or 0.1-0.01 M $\Omega$ (Gurnell and Fenn, 1985; De Mora and others, 1994; Vandal and others, 1998; Lyons and others, 2013). Combined with a tether resistance of $200 \Omega$ (personal communication from E. Waugh, 2012) this would give a total resistance of $0.1002 \mathrm{M} \Omega$ between two contacts $1 \mathrm{~cm}$ apart assuming the lower value is chosen. A supply voltage of $200 \mathrm{~V}$ d.c. would induce a current of $1.9 \mathrm{~mA}$ to flow between the two terminals on meeting the water surface, an easily detectable current with most modern metering equipment. While these currents are low compared with shorting in more conductive environments (e.g. sea water), it is the experience of one of the authors on other tethered sampling systems over longer cable lengths and with similar d.c. input voltages, that currents exceeding $1 \mathrm{~A}$ can be drawn in the event of a short.

While not used in the final assembly due to a last-minute breakage, provision for a water contact switch was made by installing appropriate electrical connections and a suitably tapped penetration of the lower flange to mount a two-pin male connector (Teledyne Impulse XSG-PBCLM) on the base plate of the lamp unit to act as a simple water contact switch, with the option to interface with more sophisticated detection systems as an alternative for non-conductive environments. The penetration was subsequently blanked off and the risk of water contact managed through other means (see Section 3.7).

\subsection{Light output calculations}

It is established that exposure to UV light inactivates bacteria (Andrew, 2005; Labas and others, 2006). DNA strongly absorbs radiation at wavelengths in the vicinity of
200-250 nM, changing the mode of operation of nucleic acids in the organism and disrupting their ability to propagate. They become biologically inactive (Andrew, 2005; Gayán and others, 2011). At shorter wavelengths secondary effects can also occur when ozone and hydroxyl groups can form that have an additional germicidal effect (Bekdash and others, 1996).

UV radiation at these wavelengths can be produced by various methods, striking an arc through mercury vapour at low pressure (Bekdash and others, 1996; Heering, 2004), pulsed UV sources (Bohrerova and others, 2008), cold plasma jets (Abramzon and others, 2006) and deep-UV light-emitting diodes (Yagi and others, 2007; Shur and Gaska, 2010; Bowker and others, 2011).

In the present case, LPM vapour lamps (GE T8 G13 base $55 \mathrm{~W}$ Germicidal lamps - Primark G55T8-GE), in association with electronic dual lamp ballasts $(2 \times 55 \mathrm{~W}$ Tridonic Electronic ballasts - Primark PC2/55TC-LBE) were chosen for their size, availability and relatively high UV output $(18 \mathrm{~W}$ at $254 \mathrm{~nm})$ compared with other available lamps.

The reactor was formed from a set of individual lamps arranged in a circle around a central column. Consequently any point above the reactor surface will be exposed to the output of 6-7 lamps of the full complement of 12, and will be shadowed from the full output of all but the adjacent lamp.

Radiant energy passing through a three-dimensional point, or volume element, from all directions is defined as the fluence rate for that point and is expressed in $\mathrm{Wm}^{-2}$ (Bolton, 2000). UV dose, or fluence, through this volume element is the fluence rate multiplied by the irradiation time and is given in $\mathrm{J} \mathrm{m}^{-2}$ (Bolton, 2000).

Qualls and Johnson (1983) and Bolton (2000) give equations for calculating UV fluence and dose from cylindrical reactors with linear light sources based on the multiple point source summation (MPSS) method (Jacobm and Danoff, 1970; Qualls and Johnson, 1983; Bolton, 2000). Under MPSS a linear lamp is divided into smaller subunits, and the radiant power of the source divided evenly between them. Their individual contribution to the fluence rate 
through a volume element is calculated taking account of their distance from, and angle of incidence to, the volume element. These individual results are then summed to determine the total fluence rate at the volume element.

Both Qualls and Johnson (1983) and Bolton (2000) assume a single linear lamp; however, in the present case, multiple linear lamps contribute variously to the UV fluence at the volume element. Accordingly, for the purpose of calculation, it was assumed that the lamp closest to the chosen volume element contributed $100 \%$ of its output, each lamp of the pair bracketing this lamp contributed $75 \%$ of its output (i.e. $2 \times 0.75=1.5$ lamps for the pair), and the next pair contributed $45 \%$ each $(2 \times 0.45=0.9$ of a lamp for the pair). The third pair is taken to be completely shadowed by intervening lamps from the measurement point and was not accounted for in this simplified estimation but will contribute to the reflected irradiative background.

Under these working assumptions, the output from each lamp was calculated separately with the MPSS method using $5 \mathrm{~cm}$ long lamp subunits, for a volume element $9 \mathrm{~cm}$ from the reactor surface and midway, longitudinally, along the lamp. This point was chosen because it was the distance where the wall of the borehole would be expected to be during deployment. These individual lamp outputs were then combined to estimate the total fluence rate through the volume element. The calculation was run twice, once using the Bolton (2000) and once using the Qualls and Johnson (1983) equation as a means of sense-checking the magnitude of the result.

Equation (1) was used first (simplified after Bolton, 2000) to calculate the contribution of each subsection of lamp to the fluence at the volume element.

$E^{\prime}(x, H)=\frac{\Phi}{4 \pi L x}\left[\arctan \left(\frac{(L / 2)+H}{x}\right)+\arctan \left(\frac{(L / 2)-H}{x}\right)\right]$

where $E^{\prime}$ is the fluence rate at a radial distance $x$ and a longitudinal distance $H$ above the centre of the lamp. $L$ is the length of the lamp $(95.3 \mathrm{~cm})$ and $\Phi$ is the source's radiant power (18 W at $254 \mathrm{~nm})$.

Thus, for each lamp the output is given as the sum of these point sources:

$$
E_{\text {lamp }}=\sum_{H_{n}}^{H_{0}} E^{\prime}(x, H)
$$

To calculate total reactor output, these individual lamp results were combined as follows:

$$
E_{\text {total }}=\left[E_{\text {lamp }}+2\left(0.75 E_{\text {lamp }}\right)+2\left(0.45 E_{\text {lamp }}\right)\right]
$$

therefore

$$
\begin{aligned}
& E_{\text {total }}=(5.18+6.17+3.35) \cdot 0.9 \\
& E_{\text {total }}=13.23 \mathrm{~mW} \mathrm{~cm}^{-2}
\end{aligned}
$$

This model neglects reflection and refraction by the quartz tube, and transmission loss through the quartz is accounted for after the fluence rate calculation as recommended in Bolton (2000) by degrading by $10 \%$.

The next equation used was (Qualls and Johnson, 1983)

$$
I_{\left(\mathrm{Z}_{\mathrm{L}}\right)\left(R, \mathrm{Z}_{\mathrm{C}}\right)}=\frac{S}{4 \pi\left(R^{2}+Z_{\mathrm{LC}}^{2}\right)} \exp \left[-\mathrm{a}\left(R-R_{1}\right) \frac{P}{R}\right]
$$

Equation (2) gives the intensity $(I)$ at a point $\left(R, Z_{\mathrm{C}}\right)$ near the lamp (the volume element) from a point source, $Z_{\mathrm{L}}$, from the base of the linear lamp. The term $a$ is the absorbance of the medium between the lamp surface and the volume element, which was treated as zero since the transmission loss through dry air over the short distances involved is zero. After the calculation, as in Eqn (1), account was taken of the $10 \%$ transmission loss through quartz by multiplying the result by 0.9 .

The total intensity at point $I_{\left(R, Z_{C}\right)}$ is the sum of the contributions of each point source (at each $Z_{\mathrm{L}}$ ) over the source length,

$$
I_{\left(R, Z_{C}\right)}=\sum_{Z_{L_{n}}}^{Z_{L_{1}}} I_{\left(Z_{\mathrm{L}}\right) \cdot\left(R, Z_{\mathrm{C}}\right)}
$$

and the total fluence through a volume element is calculated for the pairs of lamps capable of directly radiating the area, so

$$
I_{\text {total }}=\left(I_{\left(R, Z_{C}\right)}\right)+2\left(0.75 I_{\left(R, Z_{C}\right)}\right)+2\left(0.45 I_{\left(R, Z_{C}\right)}\right) \cdot 0.9
$$

Therefore

$$
\begin{aligned}
& I_{\text {total }}=(5.51+6.56+3.55) \cdot 0.9 \\
& I_{\text {total }}=14.06 \mathrm{~mW} \mathrm{~cm}^{-2}
\end{aligned}
$$

Both equations agreed, within a small margin, with each other at 13.23 and $14.06 \mathrm{~mW} \mathrm{~cm}^{-2}$ respectively.

\subsection{Dose}

As the lamp is lowered down the shaft, the UV dose delivered to the borehole walls depends on the rate at which it is lowered. The exposure period begins with the lower part of the lamp passing the volume element and ends as the upper end passes it by. The time nominally allocated to the borehole disinfection stage was $30 \mathrm{~min}$ and the borehole was calculated to be air-filled for the first 270-300 m (Siegert and others, 2012). In order to cover this distance in the allocated time, the lamp needs to descend $1 \mathrm{~m}(6 \mathrm{~s})^{-1}$,

$$
\begin{aligned}
\text { Dose }\left(\mathrm{mJ} \mathrm{cm}^{-2}\right)= & \text { Fluence }\left(\mathrm{mW} \mathrm{cm}^{-2}\right) \\
& \text {. Exposure time }\left(\mathrm{s}^{-1}\right)
\end{aligned}
$$

and exposure time is given by the length of the incandescent part of the reactor multiplied by the descent rate. Thus

$$
76.44 \mathrm{~mJ} \mathrm{~cm}^{-2}=13.23 \mathrm{~mW} \mathrm{~cm}^{-2} \cdot(0.963 \mathrm{~m} \cdot 6) \mathrm{s}^{-1}
$$

is the dose for a volume element on the borehole wall during the downward transit of the reactor through the airspace at the target descent rate. This rate was chosen so an effective dose could be delivered on the downward transit only, to guard against the small risk of the lamp being extinguished on contact with the water at the hydrostatic head.

The dose required for disinfection will vary depending on the organism under consideration (Qualls and Johnson, 1983; Bekdash and others, 1996; Andrew, 2005; Guivan and others, 2010). Furthermore, disinfection is not an absolute term but a statistical concept representing a particular level of microbial inactivation, most commonly interpreted as a reduction in the ability of bacteria to form colonies.

'Complete destruction', defined by the US Environmental Protection Agency and reviewed by Bekdash and others (1996), is a $\log 3$ reduction (99.9\% inactivation) and requires doses of $3.4-26.4 \mathrm{~m} \mathrm{~cm}^{-2}$ for most common bacteria (Bacillus subtilis is commonly used as the definitive test subject because it is one of the most persistent types). Mould spores are the hardest to inactivate, some requiring $>300 \mathrm{~m} \mathrm{~cm}^{-2}$ to achieve $\log 3$ inactivation (Bekdash and others, 1996). Log 3 inactivation is considered a safe level 
for drinking water from a municipal supply, and the standards set for prevention of forward contamination might be expected to be more stringent. As previously mentioned, the CPESESSE recommends not exceeding $10^{2}$ cells $\mathrm{mL}^{-1}$ based on the basal ice concentrations found in accretion ice at Vostok Subglacial Lake (Christner and others, 2006). Interestingly that study found that the bacterial density of the accretion ice was 2-7 times greater than that of the overlying glacial ice, implying a lake source for the bacterial carbon found within (Christner and others, 2006). Priscu and others (1999) found concentrations between $2.8 \times 10^{3}$ and $3.6 \times 10^{4}$ cells $\mathrm{mL}^{-1}$ at $3590 \mathrm{~m}$ below the surface from the same site $\sim 500 \mathrm{~m}$ higher up the core.

A number of studies have sought to characterize the microbial communities in different surface environments on the Antarctic continent, and glacial ice in general, though mostly these deal with community diversity and few report cell density unless these are for soil bacteria or those found in liquid water such as melt ponds (Karl and others, 1999; Priscu and others, 1999; Christner and others, 2000, 2001; Jungblut and others, 2005; Yergeau and others, 2007; Lanoil and others, 2009). Bulat does report cell concentrations from snow and ice above Vostok Subglacial Lake from the surface to $\sim 100 \mathrm{~m}$ below the surface, giving values ranging from 0.02 to 1.9 cells $\mathrm{mL}^{-1}$ (Bulat and others, 2011), indicating that cell densities may already be below those considered acceptable by the CPESESSE guidelines, and indicates that the major sources of potential contamination may well be brought to the site by the drilling and scientific activities themselves.

One wide survey of microbial communities across a range of habitat in Antarctica has shown the Ellsworth Mountains area to be a separate biogeographic region characterized by extremely low nutrient input and exposure to high UV levels during the summer (Yergeau and others, 2007). Bacterial counts and biomass were low, consistent with the observation of Bulat and others (2011) at Vostok, and the community structure is narrow, skewed toward dominance by Bacteroidetes of the order Sphingobacteriales, the vast majority of these being related to the genus Chitinophaga (Yergeau and others, 2007). The order Sphingobacteriales are the dominant bacterial group in Antarctic microbial soil communities and are common globally (Roesch and others, 2012).

Yergeau and others (2007) surmised that these species dominate because they possess a combination of environmental hardiness and a specialized metabolism more adapted to the low nutrient availability. Potentially these resistant characteristics include a higher than normal resistance to UV radiation given the high UV regime in this environment, a factor that tends to skew community structure towards resistant strains (Manrique and others, 2012).

From these preliminary calculations the design would appear to exceed a $\log 3$ reduction when coupled with a descent rate of $10 \mathrm{~m} \mathrm{~min}^{-1}$. Further, given the low cell density that might be expected in this area based on surface densities given in the literature, such a reduction would serve to maintain viable cell density below the $10^{2}$ cells $\mathrm{mL}^{-1}$ recommended by the CPESESSE. A further safeguard in the spirit of the committee's Recommendation 13 would be to sample and determine bacterial cell density directly at the locale prior to conducting a UV reactor deployment. Using the calculated UV flux given in this paper, a lowering rate and exposure time could easily be determined to deliver the appropriate dose should local bacteria densities exceed the recommended guidelines or exogenous sources lead to this situation arising.

While the primary purpose of this reactor was to disinfect the walls and airspace of the borehole, it is interesting to briefly contemplate the transmission of UV radiation into the surrounding snow and ice since material dislodged from the borehole walls, if heavily contaminated, may pose a possible vector for forward contamination if carried into the lake by sampling equipment. A limited survey of the extensive literature on the subject indicates that compacted glacial ice is fairly transparent to short-wavelength light with an absorption coefficient of $0.092 \mathrm{~m}^{-1}$ (transmission maximum) at $400 \mathrm{~nm}$, climbing to an absorption coefficient of $0.665 \mathrm{~m}^{-1}$ at $250 \mathrm{~nm}$ and attenuating strongly below $170 \mathrm{~nm}$ (Perovich and Govoni, 1991). Warren and others (2006) reported the difficulty in even obtaining transmission coefficients in lake ice over path lengths of $0.5 \mathrm{~m}$ due to the optical clarity of the ice at wavelengths down to $313 \mathrm{~nm}$. Snow offers a slightly more complex optical environment due to its granular nature and is a highly scattering medium attenuating transmission in the visible spectrum and favouring shorter-wavelength transmission (Warren and others, 2006; Perovich, 2007). Additionally there are structural differences between new snow, characterized by a combination of needles, rounded grains and small plates, and old snow which is primarily composed of rounded grains, and these affect attenuation and scattering. New snow has lower transmission coefficients than old snow, mainly due to high reflectance. Bubbles and particulate material will also attenuate transmission (Warren and others, 2006; Perovich, 2007; Rasmus and Huttunen, 2009). From these studies and the calculated output of the UV reactor, we might expect $\log 3$ deactivation to occur a reasonable distance into the surrounding ice, less so in the upper parts of the borehole where the structure is predominantly old snow, and least at the surface, where the snow will be newest. This suggests recommending a methodology of differential lowering speeds depending on depth if a spatially uniform UV penetration to any chosen level of deactivation were to be achieved over the entire length of the shaft to the hydrostatic head.

\subsection{Deployment risk assessments}

The lamp is the first component of the scientific payload to enter the borehole after it has been formed. Consequently it is a test case for the subsequent deployment of other equipment. It is uncertain where the actual level of the water will be in the shaft since that will depend on a number of difficult-to-calculate factors that will determine the actual head of the lake once the ice barrier had been broached. The head pressure will be a combination of the density of overlying ice, influent/supply water pressure and pressuredissipating mechanisms within the hydraulic system. Working calculations by team engineers estimate the water level will stabilize 270-300 m below the surface of the ice (Siegert and others, 2012).

The UV lamp assembly is assigned a nominal IP68 rating based on the specification of components used at its most vulnerable points. These are the gland seals around the central cooling shaft and its concentric cable duct. Under normal circumstances these should be able to withstand a brief immersion to $1 \mathrm{~m}$ but they are not rated for greater depths, nor can they be relied on for any length of time. No seal is entirely reliable and they become less so as temperatures drop, O-ring seals harden and metals contract. 


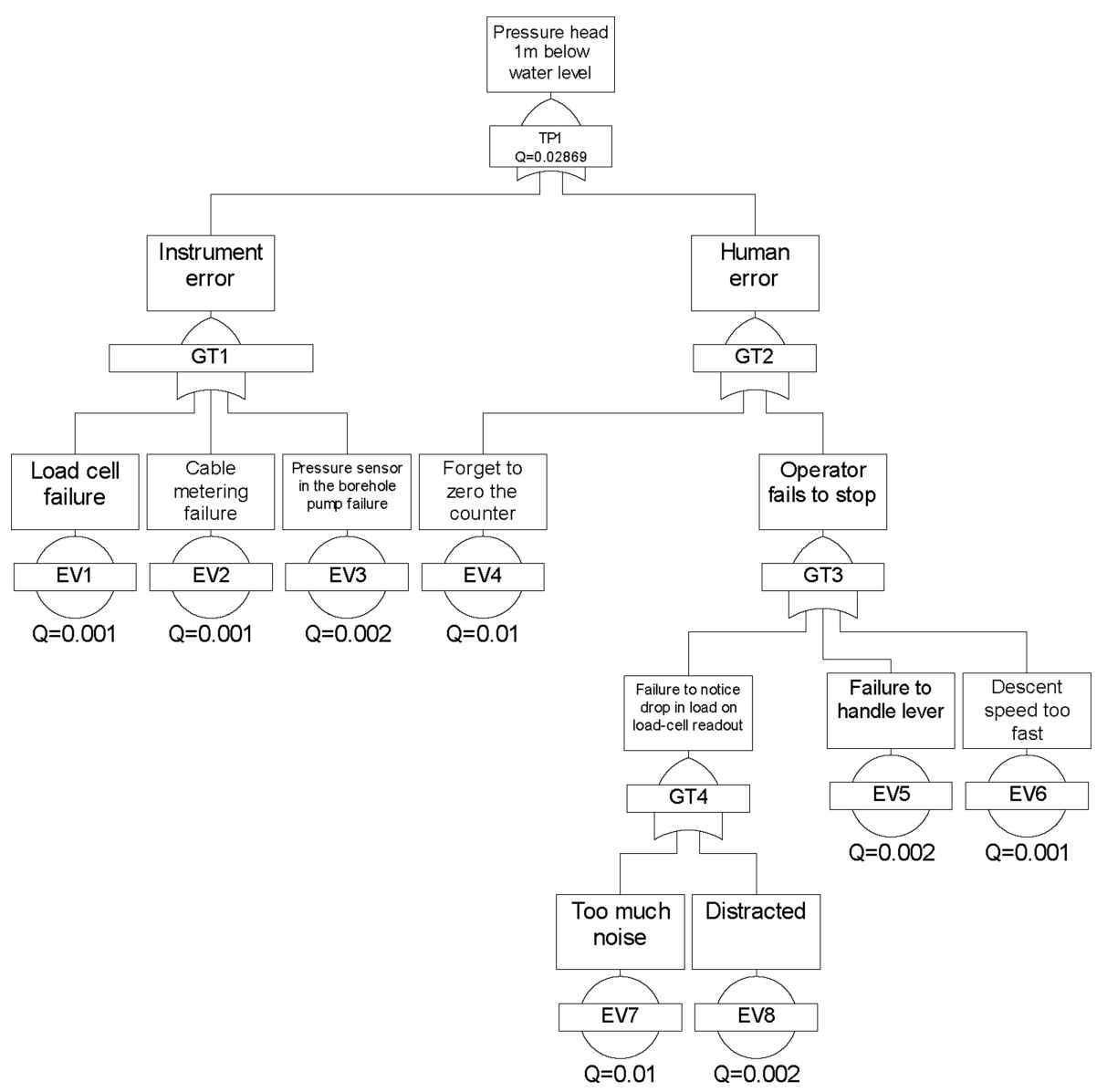

Fig. 2. UV-lamp fault tree and final relative probabilities.

Consequently it was considered prudent to avoid immersion of the lamp at the bottom of the shaft if at all possible.

As reported in Section 3.4, the original design allowed for a water contact switch to alert personnel when the base of the lamp made contact with water. In the event of this becoming inoperable, reserve measures and contingencies needed to be available to avoid more than partial immersion of the unit.

The first feature in favour of mitigating the risk is that the lamp assembly displaces more than its own weight in water and would float provided the seals do not leak. However, the unit is attached to heavy tooling cable, which will force the unit further down if it continues to be paid out, resulting in an unplanned immersion.

Another available safeguard is the presence of a load cell on the outboard sheave of the deployment winch which has sufficient sensitivity to detect the load coming off the cable as the UV lamp assembly became buoyant. The use of the load cell, however, relies on the winch operator being aware of the change in the numerical readout on the display at the time the unit enters the water and becomes buoyant. This is aided by a line-out measurement taken from a counter that records the number of rotations of the outboard sheave, allowing the winch operator to know exactly how much cable has been paid out so they can be extra vigilant when approaching the depth of the calculated pressure head.

Based on all sources of information, procedures were derived and formal risk assessment carried out. Probability values were then assigned to the relative likelihood of certain scenarios playing out. These are represented in the fault tree presented in Figure 2.
A fault tree is a well-known method for modelling and estimating the reliability of a system where the likelihood of system failure depends on the likelihood of several potential modes of failure (O'Connor, 2005). In addition to providing a visual, easy-to-understand interpretation of how a failure mode may propagate in the system, a fault tree also uses sound probability theory to compute the likelihood of the top failure event ever taking place.

In such diagrams, the logic probability functions are captured in 'and' or 'or' gates. An 'and' gate represents the scenario where all base failure modes need to occur in order for the top failure event to realise; an 'or' gate represents the scenario where only one failure event needs to occur in order for the top failure event to realise. Figure 2 shows that the top-level failure event, failure to maintain the pressure head over the lowest seal at $<1 \mathrm{~m}$ below water level, can be caused by instrument failure or human error. Based on the assessments provided for each failure mode, we were able to estimate the likelihood of failure to keep the pressure head $1 \mathrm{~m}$ below water level as 0.029 . This equates to a chance of approximately 1 in every 34 deployments. Human error is the most likely failure mode at level 1 . The most likely causes for human error are: (1) operator forgets to zero the wire counter and (2) operator fails to notice the drop on the load cell by being distracted, or because there is too much noise in the load-cell output to distinguish a signal originating from the change in load from the background fluctuation in the display.

The fault tree contains only 'or' gates. Failure to keep the pressure head $<1 \mathrm{~m}$ below water level can be caused by any of the eight base failure modes. As a result, the reactor 


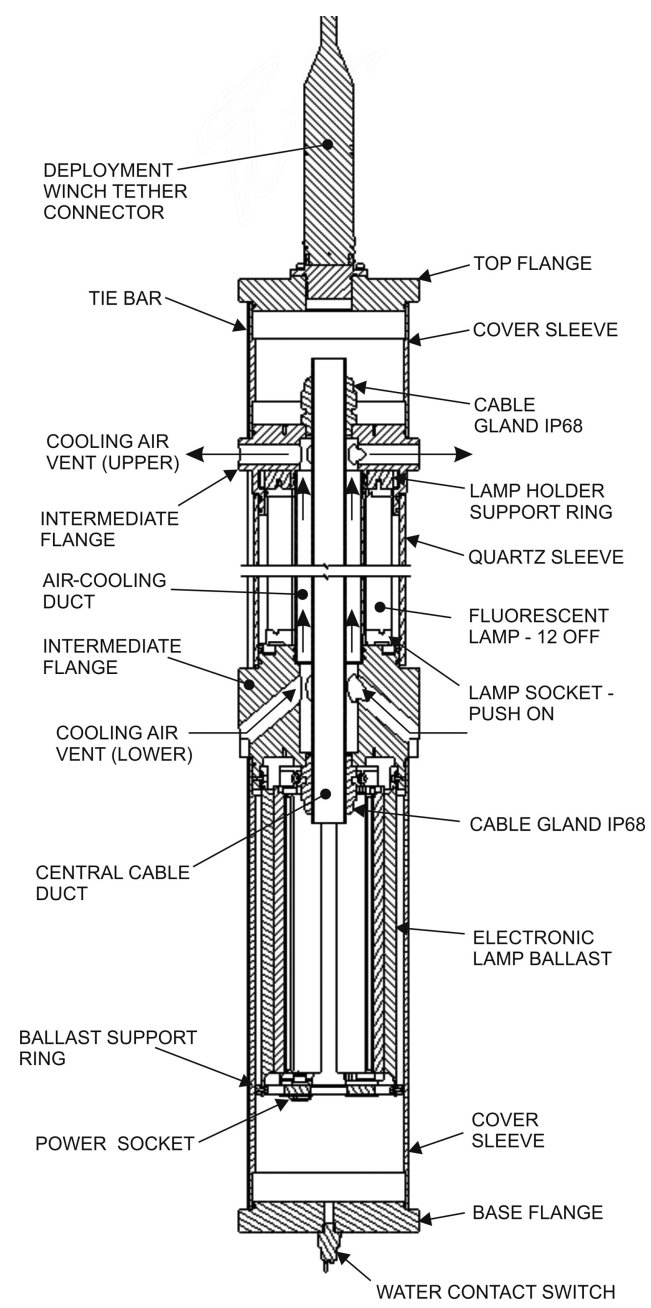

Fig. 3. Final UV lamp assembly.

deployment sequence was defined by taking into account mitigation actions for these base failure modes at different phases of the deployment (personal communication from K. Saw, 2012).

\section{DETAILED DESCRIPTION OF THE DESIGN}

The lamp's design can be summarized as being a single quartz glass tubing section with a chamber either end and two, internal, concentric aluminium tubes providing a water-resistant air duct up the middle of the structure and ducting for electrical cables down the centre of the assembly (see Fig. 3). Arranged radially around the air duct and within the wall of the quartz tube are 12 T8 fluorescent tubes emitting $18 \mathrm{~W}$ of UV radiation $(254 \mathrm{~nm})$ each. The top flange accommodates a multi-way bulkhead connector supplying power and signal connections from the surface. These are internally routed via a four-conductor cable to the bottom chamber that houses six dual-lamp electronic ballasts. These are supplied with a d.c. voltage of at least $180 \mathrm{~V}$ d.c. Incoming power is connected via multi-pole bulkhead connectors in the lower section of the bottom chamber to distribute power between the six ballasts that control two low-pressure mercury lamps each. Multiple solid-core switchgear wires returned power up the central conduit from each ballast to complete the lamp circuit. Each conductor in this loom has a cross-sectional area of $1 \mathrm{~mm}^{2}$ and is capable of conducting $15 \mathrm{~A}$ at $600 \mathrm{~V}$.
Electrical connections are isolated from chassis components by $30 \%$ glass-filled PEEK insulating inserts to prevent any bare wires from contacting the metal casing of the assembly. The entire circuit was protected at the power supply by residual current detection devices and connection to a common ground.

The wiring was modularized to allow disassembly of each end separately, should any maintenance be required, with in-line and bulkhead connectors at strategic points.

\section{DISCUSSION}

This UV reactor was designed and built so that the Lake Ellsworth Consortium had a means of borehole disinfection to meet the aims, and the spirit, of the SCAR and the NRC principles of environmental stewardship for the exploration and study of subglacial aquatic environments. These principles call for contamination reduction technology at every step of the lake access process (Antarctic Treaty Consultative Parties, 1991; Siegert and others, 2012). Contamination, whether chemical or biological, has the potential to alter these environments, confound interpretation of samples and limit the degree to which we might understand the nature and functioning of these environments (Siegert and others, 2012; Priscu and others, 2013; Wadham, 2013). The implementation of the consortium's decision to provide this technology was undertaken late in the preparation stages of a 2012 attempt to access and sample the lake. As a result, this reactor is a form of rapid prototyping and no time was available following assembly to comprehensively test the apparatus other than to confirm it operated. The reactor was run for a short period ( $60 \mathrm{~min}$ ) in a refrigerated container $\left(-20^{\circ} \mathrm{C}\right)$ after equilibrating to this temperature overnight. This test was conducted using the same power supply and a similar test cable, proving that the unit would strike up and run in temperatures equivalent to Antarctic ambient temperatures, though no attempt to measure the fluence rate could be made due to a lack of calibrated test apparatus or time to conduct an exhaustive series of measurements.

While lake access was not successful on this occasion, the scientific objectives remain relevant and it is expected that another attempt will be made in the future, so there may be the opportunity to conduct more comprehensive tests at a later date under simulated environmental conditions.

Refreezing of an ice hole can take just a few tens of hours depending on the diameter and depth of the hole (Makinson, 1994). This leaves limited time to prepare for clean access to the borehole once drilling has been completed; UV disinfection of the air-filled headspace is a component of that process. Therefore it was an important feature of any disinfection system that an effective dose is delivered in the shortest time possible. The calculations conducted in this paper indicate that a transit time of $30 \mathrm{~min}$, in addition to a recovery period, would be sufficient to deliver a dose far in excess of that required to achieve a $\log 3$ disinfection for most common bacteria. This was achieved at relatively low cost with commercially available UV sources. Their availability fitted well with the short production time frame.

Research conducted, in preparation for this project, into other technologies indicates pulsed UV sources are extremely effective (Bohrerova and others, 2008), and mediumpressure xenon and iodine vapour lamps, which concentrate output at $\sim 253.7 \mathrm{~nm}$ (the most potent wavelength for 
bacterial inactivation), are also proving more effective than LPM lamps without the hazards inherent in using mercury (Guivan and others, 2010). The pulsed UV methods are of particular interest. The dose from a pulsed UV source is of high intensity on a very short duty cycle that can be repeated until the required dose is achieved. As a result, these types of lamp are not prone to the same accumulation of heat as are the LPM tubes, and through control of the pulse sequence there is the potential to excite vulnerable molecules and proteins at frequencies, and in sequences, that maximize the potential for disruption. However, both these systems had much greater lead times, and would have required significant re-engineering of the light source and power supply to fit within the geometric constraint of the sterile airlock delivery system. On balance, then, not only was the system presented in this paper far less expensive than other options, it required less re-engineering of primary components and could be delivered in a much shorter time frame.

There are currently several unknowns on the performance of the lamp, and a comprehensive test programme would be a logical next step in proving the efficacy of this technology in this deployment scenario. As mentioned, UV output is dependent in part on temperature and we did not have the opportunity to characterize the output under a representative range of temperature. The balance between the endogenous heat output of the lamp and the heat dissipation measures would determine the effect this has on the UV dose capable of being delivered. Consequently, we must, for the time being, rely on the generosity of our safety factors for surety that we can achieve effective disinfection doses.

It would also be useful to confirm the accuracy of our calculations in the context of work done recently by Li and others $(2012,2013)$ that supports the assumption made in this paper that adjacent fluorescent tubes in a circular reactor shadow volume elements from the full output of all lamps. Li and others (2012, 2013) modelled and experimented with a three-lamp scenario and it would be interesting to extend and compare their findings to the lamp described in this paper through a series of measurements under controlled conditions.

We believe there is the potential to repurpose this lowcost technology to be a component of systems for clean access to other pristine environments, particularly, though not exclusively, to scenarios involving a frozen fluid. When an internal volume requires disinfection, and access to the volume is confined, this apparatus could easily be applied, especially when an annular design provides the most effective way of accessing a space and delivering a UV dose.

\section{ACKNOWLEDGEMENTS}

We acknowledge the numerous friends, colleagues and reviewers who contributed to improving the manuscript with comments and suggestions, in particular James Wyatt for providing the illustrations of the equipment, Nicholas Rundle for formulating the original design brief, and Medtech Design Services Ltd for draughting support during the project.

\section{REFERENCES}

Abramzon N, Joaquin JC, Bray J and Brelles-Marino G (2006) Biofilm destruction by RF high-pressure cold plasma jet. IEEE Trans. Plasma Sci., 34(4), 1304-1309 (doi: 10.1109/TPS.2006.877515)
Alekhina I and 7 others (2011) Code of Conduct for the Exploration and Research of Subglacial Aquatic Environments. (Codes of Conduct for Fieldwork, Animals and SAEs 3) Scientific Committee on Antarctic Research, Cambridge

Andrew R (2005) Ultraviolet water disinfection: it's all about the dose. Water Condition. Purific. Mag., 47(5), 38-39

Antarctic Treaty Consultative Parties (1991) Protocol on Environmental Protection to the Antarctic Treaty (Environmental Protocol or Madrid Protocol). Antarctic Treaty Consultative Parties, Madrid

Bekdash F, Kurth L and Solomon L (1996) Ultraviolet light disinfection technology in drinking water application - an overview. (EPA 811-R-96-002) US Environmental Protection Agency, Washington, DC

Bohrerova Z, Shemer H, Lantis R, Impellitteri CA and Linden KG (2008) Comparative disinfection efficiency of pulsed and continuous-wave UV irradiation technologies. Water Res., 42(12), 2975-2982 (doi: 10.1016/j.watres.2008.04.00)

Bolton JR (2000) Calculation of ultraviolet fluence rate distributions in an annular reactor: significance of refraction and reflection. Water Res., 34(13), 3315-3324 (doi: 10.1016/S00431354(00)00087-7)

Bowker C, Sain A, Shatalov M and Ducoste J (2011) Microbial UV fluence-response assessment using a novel UV-LED collimated beam system. Water Res., 45(5), 2011-2019 (doi: 10.1016/ j.watres.2010.12.005)

Brito MP, Griffiths G, Mowlem M and Makinson K (2013) Estimating and managing blowout risk during access to subglacial Antarctic lakes. Antarct. Sci., 25(1), 107-118 (doi: 10.1017/S0954102012000442)

Bulat SA, Alekhina IA, Marie D, Martins J and Petit JR (2011) Searching for life in extreme environments relevant to Jovian's Europa: lessons from subglacial ice studies at Lake Vostok (East Antarctica). Adv. Space Res., 48(4), 697-701 (doi: 10.1016/ j.asr.2010.11.024)

Christner BC, Mosley-Thompson E, Thompson LG, Zagorodnov V, Sandman K and Reeve JN (2000) Recovery and identification of viable bacteria immured in glacial ice. Icarus, 144(2), 479-485 (doi: 10.1006/icar.1999.6288)

Christner BC, Mosley-Thompson E, Thompson LG and Reeve JN (2001) Isolation of bacteria and 16S rDNAs from Lake Vostok accretion ice. Environ. Microbiol., 3(9), 570-579 (doi: 10.1046/ j.1462-2920.2001.00226.x)

Christner BC and 9 others (2006) Limnological conditions in Subglacial Lake Vostok, Antarctica. Limnol. Oceanogr., 51(6), 2485-2501 (doi: 10.4319/lo.2006.51.6.2485)

Clancy EV (1993) Thermal characterization of fluorescent fixtures. In Conference Record of the 1993 IEEE Industry Applications Society Annual Meeting, 2-8 October 1993, Toronto, Ontario, Canada, Vol. 3. Institute of Electrical and Electronics Engineers, Piscataway, NJ, 2331-2333

De Jong BHWS, Beerkens RGC, Van Nijnatten PA and Le Bourhis E (2000) Glass, 1. Fundamentals. In Ullmann F, Gerhartz W, Yamamoto YS, Campbell FT, Pfefferkorn R and Rounsaville JF eds. Ullman's encyclopedia of industrial chemistry. Wiley- $\mathrm{VCH}$, Weinheim

De Mora SJ, Whitehead RF and Gregory M (1994) The chemical composition of glacial melt water ponds and streams on the McMurdo Ice Shelf, Antarctica. Antarct. Sci., 6(1), 17-27 (doi: 10.1017/S0954102094000039)

Dowdeswell JA and Siegert MJ (2002) The physiography of modern Antarctic subglacial lakes. Global Planet. Change, 35(3-4), 221-236 (doi: 10.1016/S0921-8181(02)00128-5)

Gardner DWM and Shama G (1999) UV intensity measurement and modelling and disinfection performance prediction for irradiation of solid surfaces with UV light. Food Bioprod. Process., 77(3), 232-242 (doi: 10.1205/096030899532510)

Gayán E, Monfort S, Álvarez I and Condón S (2011) UV-C inactivation of Escherichia coli at different temperatures. Innovat. Food Sci. Emerg. Technol., 12(4), 531-541 (doi: 10.1016/j.ifset.2011.07.008) 
Gluskin E (1999) The fluorescent lamp circuit. IEEE Trans. Circuits Syst. I: Fund. Theory Appl., 46(5), 529-544 (doi: 10.1109/ 81.762919)

Graovac M, Dawson FP, Fila M and Cormack DE (1998) Fluorescent lamp cold environment performance improvement. In Proceedings of the 33rd Annual Meeting of the Industry Applications Conference 1998, 12-15 October, 1998, St Louis, MO, USA. Institution of Electrical and Electronics Engineers, Piscataway, NJ, 2158-2163

Guivan MM, Kamikozawa T, Kurokawa H, Motomura H, Kadowaki $K$ and Jinno M (2010) Comparative inactivation of Bacillus subtilis spores using a DBD-driven Xenon lodide Excilamp and a conventional mercury lamp. IEEE Trans. Plasma Sci., 38(8), 1972-1977 (doi: 10.1109/TPS.2010.2044588)

Gurnell AM and Fenn CR (1985) Spatial and temporal variations in electrical conductivity in a pro-glacial stream system. J. Glaciol., 31(108), 108-114

Heering W (2004) UV sources - basics, properties and applications. IUVA News, 6(1), 7-13

Jacobm SM and Danoff JS (1970) Light intensity profiles in a perfectly mixed photoreactor. AlChE J., 16(3), 359-363 (doi: 10.1002/aic.690160309)

Jungblut AD and 6 others (2005) Diversity within cyanobacterial mat communities in variable salinity meltwater ponds of McMurdo Ice Shelf, Antarctica. Environ. Microbiol., 7(4), 519-529 (doi: 10.1111/j.1462-2920.2005.00717.x)

Karl DM, Bird DF, Bjorkman K, Houlihan T, Shackelford R and Tupas L (1999) Microorganisms in the accreted ice of Lake Vostok, Antarctica. Science, 286(5447), 2144-2147 (doi: 10.1126/science.286.5447.2144)

Labas MD, Brandi RJ, Martín CA and Cassano AE (2006) Kinetics of bacteria inactivation employing UV radiation under clear water conditions. Chem. Eng. J., 121(2-3), 135-145 (doi: 10.1016/ j.cej.2006.05.012)

Lanoil B and 7 others (2009) Bacteria beneath the West Antarctic Ice Sheet. Environ. Microbiol., 11(3), 609-615 (doi: 10.1111/ j.1462-2920.2008.01831.x)

Li M, Qiang Z, Bolton JR and Ben W (2012) Impact of reflection on the fluence rate distribution in a UV reactor with various inner walls as measured using a micro-fluorescent silica detector. Water Res., 46(11), 3595-3602 (doi: 10.1016/j.watres. 2012.04.004)

Li M, Qiang Z and Bolton JR (2013) In situ detailed fluence rate distributions in a UV reactor with multiple low-pressure lamps: comparison of experimental and model results. Chem. Eng. J., 214, 55-62 (doi: 10.1016/j.cej.2012.10.024)

Lyons WB and 6 others (2013) The carbon stable isotope biogeochemistry of streams, Taylor Valley, Antarctica. Appl. Geochem., 32, 26-36 (doi: 10.1016/j.apgeochem.2012.08.019)

Makinson K (1994) BAS hot water drilling on Ronne Ice Shelf, Antarctica. Mem. Natl Inst. Polar Res., Special Issue 49, 192-202

Manrique JM, Calvo AY, Halac SR, Villafañe VE, Jones LR and Heibling EW (2012) Effects of UV radiation on the taxonomic composition of natural bacterioplankton communities from Bahía Engaño (Patagonia, Argentina). J. Photochem. Photobiol. B, 117, 171-178 (doi: 10.1016/j.jphotobiol.2012.09.019)

National Research Council (NRC) (2007) Exploration of Antarctic subglacial aquatic environments: environmental and scientific stewardship. National Academies Press, Washington, DC

O'Connor PDT (2005) Practical reliability engineering, 4th edn. Wiley, Chichester

Perovich DK (2007) Light reflection and transmission by a temperate snow cover. J. Glaciol., 53(181), 201-210 (doi: 10.3189/ 172756507782202919)
Perovich DK and Govoni JW (1991) Absorption coefficients of ice from 250 to 400 nm. Geophys. Res. Lett., 18(7), 1233-1235 (doi: 10.1029/91GL01642)

Priscu JC and 11 others (1999) Geomicrobiology of subglacial ice above Lake Vostok, Antarctica. Science, 286(5447), 2141-2144 (doi: 10.1126/science.286.5447.2141)

Priscu JC and 12 others (2013) A microbiologically clean strategy for access to the Whillans Ice Stream subglacial environment. Antarct. Sci., 25(5), 637-647 (doi: 10.1017/ S0954102013000035)

Qualls RG and Johnson JD (1983) Bioassay and dose measurement in UV disinfection. Appl. Environ. Microbiol., 45(3), 872-877

Rasmus K and Huttunen O (2009) Evaluating the diffuse attenuation coefficient of dry snow by using an artificial light source. Boreal Environ. Res., 14(6), 971-980

Robinson RV (1960) [Experiment in visual orientation during flights in the Antarctic]. Sovietskaia antarkticheskaia ekspeditsiia [International Bulletin of the Soviet Antarctic Expeditions], 18 [in Russian]

Roesch LFW and 10 others (2012) Soil bacterial community abundance and diversity in ice-free areas of Keller Peninsula, Antarctica. Appl. Soil Ecol., 61, 7-15 (doi: 10.1016/j.apsoil. 2012.04.009)

Shur MS and Gaska R (2010) Deep-ultraviolet light-emitting diodes. IEEE Trans. Electron Devices, 57(1), 12-25 (doi: 10.1109/ TED.2009.2033768)

Siegert MJ and 7 others (2004) Subglacial Lake Ellsworth: a candidate for in situ exploration in West Antarctica. Geophys. Res. Lett., 31(23), L23403 (doi: 10.1029/2004GL021477)

Siegert MJ and 16 others (2012) Clean access, measurement, and sampling of Ellsworth Subglacial Lake: a method for exploring deep Antarctic subglacial lake environments. Rev. Geophys., 50(RG1), RG1003 (doi: 10.1029/2011RG000361)

Vandal GM, Mason RP, McKnight D and Fitzgerald W (1998) Mercury speciation and distribution in a polar desert lake (Lake Hoare, Antarctica) and two glacial meltwater streams. Sci. Total Environ., 213(1-3), 229-237 (doi: 10.1016/S00489697(98)00095-3)

Vaughan DG, Rivera A, Woodward J, Corr H, Wendt J and Zamora R (2007) Topographic and hydrological controls on Subglacial Lake Ellsworth, West Antarctica. Geophys. Res. Lett., 34(18), L18501 (doi: 10.1029/2007GL030769)

Wadham J (2013) Probing for life at its limits: technologies for exploring the Antarctic subglacial ecosystems. In Papers from the 36th Antarctic Treaty Consultative Meeting, 22-29 May 2013, Brussels, Belgium. (SCAR Lecture BP014) Scientific Committee on Antarctic Research, Cambridge

Warren SG, Brandt RE and Grenfell TC (2006) Visible and nearultraviolet absorption spectrum of ice from transmission of solar radiation into snow. Appl. Opt., 45(21), 5320-5334 (doi: 10.1364/AO.45.005320)

Wright A and Siegert M (2012) A fourth inventory of Antarctic subglacial lakes. Antarct. Sci., 24(6), 659-664 (doi: 10.1017/ S095410201200048X)

Yagi $\mathrm{N}$ and 8 others (2007) Sterilization using $365 \mathrm{~nm}$ UV-LED. In Proceedings of the 29th Annual International Conference of the IEEE Engineering in Medicine and Biology Society (EMBS), 22-26 August 2007, Lyon, France. Institute of Electrical and Electronics Engineers, Piscataway, NJ, 5841-5844

Yergeau E, Newsham KK, Pearce DA and Kowalchuk GA (2007) Patterns of bacterial diversity across a range of Antarctic terrestrial habitats. Environ. Microbiol., 9(11), 2670-2682 (doi: 10.1111/j.1462-2920.2007.01379.x) 